\title{
Follicular Epithelial Cell-Oocyte Connection during Development of Hamster Ovarian Follicle
}

\author{
Hiroyuki SUZUKI, Ikue FUKUDA and Koji TOYOKAWA \\ Faculty of Agriculture and Life Sciences, Hirosaki University, Hirosaki-shi 036-8561, Japan
}

(Received September 25, 2000 ; Accepted January 9, 2001)

\begin{abstract}
Changes in follicular epithelial cell-oocyte connections during the development of hamster ovarian follicles were studied by scanning electron microscopy using the Osmium-DimethylsulfoxideOsmium (ODO) maceration method. Follicular development was also examined histologically. In primordial follicles, the flattened follicular epithelial cells were closely associated with the oocyte. In primary follicles, polyhedral follicular epithelial cells surrounding the oocyte possessed rarely microvillous processes. The zona pellucida (ZP) appeared between the oocyte and the surrounding follicular epithelial cells when they were proliferated by 3 layers. By ODO maceration for 1-2 days, the matrix of $\mathrm{ZP}$ in the growing preantral follicles was completely dissolved, thereby tortuous and ramified cytoplasmic processes of the follicular epithelial cells toward the oocyte were exposed. These processes increased progressively in thickness and in number as the follicle developed. In antral follicles, the cumulus cell processes were elongated, but still maintained. The ZP of the antral follicular oocyte showed increased resistance to ODO maceration compared to that of the growing follicular oocyte. Further, layered heterogeneity of the ZP was noticed in the solubility to ODO maceration, suggesting that subtle changes do occur in the properties of the $\mathrm{ZP}$ matrix during residence in the follicle. It is revealed three-dimensionally in the hamster ovarian follicles that the cytoplasmic processes of the follicular epithelial cells develop rapidly, coincidently with the ZP formation, at the early-growing follicle stage and they are maintained until the antral follicle stage.
\end{abstract}

Animal Science Journal 72 (2) : 107-116, 2001

Key words : Hamster oocyte, Follicular epithelial cells, SEM ultrastructure, ODO maceration

The mammalian ovary possesses a large number of follicles ranging from primordial to preovulatory stages $^{37)}$. Ovarian follicles have been classified into several specific stages according to their size and number of surrounding layers of follicular epithelial cells $^{27,30)}$. Follicular cell-oocyte interactions are closely related to the physiological control of various steps comprising oogenesis, including support of oocyte growth, maintenance of meiotic arrest, and the final meiotic maturation ${ }^{5,8,12,16-18,36)}$. The relationship between the oocytes and the follicular epithelial cells has been extensively studied by means of electron microscopy in cattle ${ }^{13,15-17)}$, sheep ${ }^{22)}$, pigs $^{21,23)}$, mice $^{1,8,9)}$, rats ${ }^{4,11,29)}$, rabbits ${ }^{1)}$, primates ${ }^{1,44)}$, and humans ${ }^{24)}$. These follicular epithelial cell-oocyte complexes are associated primarily by means of numerous long follicular cell processes, which are in close contact with the oolemma. In addition, considerable evidence showing that gap junctions present at these points of contact between the oocyte and follicular epithelial cell membranes has been accumulated $^{1,4,8,11)}$. However, to date only a few observations on the follicular epithelial cell-oocyte association have been made in hamsters ${ }^{41,42)}$. Our previous study demonstrated that the cumulus cells, the zona pellucida (ZP) and the vitelline membrane of the hamster oocyte matured in vivo undergo certain changes, along with the nuclear and cytoplasmic maturation ${ }^{32)}$, as well as in vivo and in vitro matured (IVM) bovine oocytes ${ }^{31,33)}$ and IVM porcine

Corresponding : Hiroyuki SUZUKI (fax : +81 (0) 172-39-3750, e-mail : suzuki@cc.hirosaki-u.ac.jp)

Anim. Sci. J. 72 (2) : 107-116, 2001 
oocytes $^{34)}$. The objective of this paper was to evaluate relevant structural changes which occur between the oocyte and associated follicular cells during follicular development in the hamster ovary, using the Osmium-Dimethylsulfoxide-Osmium (ODO) method $^{203}$ followed by scanning electron microscopy (SEM).

\section{Materials and Methods}

\section{Ovaries}

A total of 41 golden hamsters (Mesocricetus au* ratus), 10-12 weeks old, were used. They were kept under conditions of constant temperature $\left(21-23^{\circ} \mathrm{C}\right)$ and a cycle of 14-h light and 10-h dark. The stage of the estrous cycle was determined for at least two cycles by the postovulatory vaginal discharge $\mathrm{e}^{26)}$. The females were stimulated intraperitoneally by $30 \mathrm{IU}$ of pregnant mare serum gonadotropin (PMSG, TeikokuZoki Pharmaceuticals, Tokyo, Japan) at metestrus and the ovaries were collected $51 \mathrm{~h}$ after PMSG injection. Parallel cytological examination showed antral follicles at this stage which included the oocytes at germinal vesicle $(87 \%)$, Metaphase I (10\%) and Metaphase II stages (3\%). To obtain more mature oocytes, some females were stimulated by $30 \mathrm{IU}$ of human chorionic gonadotropin (hCG, Mochida Pharmaceuticals, Tokyo, Japan) at $58 \mathrm{~h}$ after PMSG injection and ovaries were dissected $10 \mathrm{~h}$ after hCG injection. The experimental design was approved by the Ethical Committee for Experimentation with Animals, Hirosaki University.

\section{Histological observations}

Two hamsters were sedated with ether and sacrificed by cervical dislocation and the ovaries were immersed into Bouin's fixative, dehydrated, and embedded in paraffin. Serial sections ( $7 \mu \mathrm{m}$ thick) were stained with hematoxylin and eosin. The stage of follicles was classified based on previous studies ${ }^{27,30)}$ with minor modifications. Briefly, the primordial stage was classified into Stage 0 and a few intermediate stages were arranged in the early stages of the follicular development in order to correspond to the number of layers of follicular epithelial cells. Diameters of the follicles (defined by the basement membrane) and the oocytes were measured in the sections showing their maximum sizes. Thickness of the ZP was also recorded.

\section{SEM observations after ODO maceration}

Following anesthesia by pentobarbital sodium, 39 hamsters were perfused via the abdominal aorta first with Ringer's solution, and then with $0.5 \%$ glutaraldehyde and $0.5 \%$ paraformaldehyde in Hanks' balanced salt solution (Gibco, Grand Island, NY) with $0.1 \%$ polyvinyl alcohol (Sigma, St. Louis, MO) (HBSS). After dissection, ovaries were processed for ultrastructural morphology as described previously $^{34)}$. Briefly, the ovaries were post-fixed in $1 \%$ osmium tetroxide $\left(\mathrm{OsO}_{4}\right)$ in $\mathrm{HBSS}$ for $1 \mathrm{~h}$. After rinsing with the buffer solution, the specimens were successively immersed in 15, 30 and $50 \%$ aqueous solutions of dimethylsulfoxide (DMSO) for $30 \mathrm{~min}$ each in order to prevent ice-crystal damage during freezing ${ }^{20)}$. Specimens were frozen on a metal plate chilled with liquid nitrogen (TF-2, Eiko Engineering, Co. Ltd., Tokyo, Japan), cracked into two parts with a razor blade and hammer, and immediately placed in a 50\% DMSO solution. After rinsing, samples were macerated in $0.1 \% \mathrm{OsO}_{4}$ in $\mathrm{HBSS}$ at $20^{\circ} \mathrm{C}$ for $1^{-3}$ days and then fixed again in $1 \% \mathrm{OsO}_{4}$ in HBSS for $1 \mathrm{~h}$. They were conductivity-stained with $2 \%$ tannic acid and $1 \% \quad \mathrm{OsO}_{4}$ solution. After dehydration in a graded ethanol scries and treatment with isoamylacetate, the specimens were critical-point dried and sputter-coated with gold. Observations were made with a JSM-5300 scanning electron microscope (JEOL, Tokyo, Japan) at an accelerating voltage at 20 $\mathrm{kV}$.

\section{Statistical analysis}

Statistical significances of diameters of the follicles and the oocytes and thickness of the ZP were analyzed by analysis of variance with the help of the BMDP program (BMDP Statistical Software, Inc., Los Angeles, CA) and Duncan's multiple range test. Values were considered statistically significant at $\mathbf{P}<$ 0.05 .

\section{Results}

A total of 1,775 follicles in serial sections of the ovaries from two hamsters were classified as summarized in Table 1. Our classification, due to the 
Table 1. Population of ovarian follicles in hamsters primed with gonadotropin

\begin{tabular}{|c|c|c|c|c|c|}
\hline \multirow[t]{3}{*}{ Stage } & \multirow{3}{*}{$\begin{array}{l}\text { Layers of follicular } \\
\text { epithelial cells }\end{array}$} & \multirow{3}{*}{$\begin{array}{l}\text { No. }(\%) \text { of } \\
\text { follicles } \\
\text { examined }\end{array}$} & \multicolumn{3}{|c|}{ Mean (range) in } \\
\hline & & & \multicolumn{2}{|c|}{ diameter $(\mu \mathrm{m})^{* *}$} & \multirow[t]{2}{*}{$\mathrm{ZP}$ thickness $(\mu \mathrm{m})$} \\
\hline & & & Follicles & Oocytes & \\
\hline 0 & Primordial follicle & $895(50.4)$ & $19(13-30)$ & $17(13-28)$ & - \\
\hline 0.5 & A few cells attached & $202(11.4)$ & $28(18-45)$ & $18(13-33)$ & - \\
\hline 1 & 1 & $131(7.4)$ & $18(30-73)$ & $26(15-40)$ & - \\
\hline 1.5 & $1-2$ & $71(4.0)$ & $75(45-108)$ & $37(25-55)$ & - \\
\hline 2 & 2 & $55(3.1)$ & $91(68-125)$ & $44(30-63)$ & - \\
\hline 2.5 & $2-3$ & $70(3.9)$ & $118(70-175)$ & $51(28-78)$ & - \\
\hline 3 & 3 & $76(4.3)$ & $147(75-225)$ & $60(38-83)$ & $1.2\left(\begin{array}{ll}0 & -3.0\end{array}\right)^{\mathrm{a}}$ \\
\hline 4 & 4 & $86(4.8)$ & $192(135-300)$ & $69(45-90)$ & $2.2(0.8-5.0)^{\mathrm{b}}$ \\
\hline 5 & $5-6$ & $63(3.5)$ & $234(150-350)$ & $74(45-90)$ & $2.2(0.8-5.0)^{\mathrm{b}}$ \\
\hline 6 & $7-8$ & $33(1.9)$ & $332(225-400)$ & $76(58-93)$ & $2.4(1.3-4.3)^{\mathrm{c}}$ \\
\hline 7 & Beginning of antrum & $20(1.1)$ & $363(280-420)$ & $75(60-100)$ & $3.0(1.3-5.0)^{\mathrm{d}}$ \\
\hline 8 & Small antral follicle & $17(1.0)$ & $416(340-550)$ & $74(60-85)$ & $3.0(2.0-7.5)^{\mathrm{d}}$ \\
\hline 9 & Intermediate antral follicle & $26(1.5)$ & $673(430-980)$ & $71(50-85)$ & $3.4(1.3-5.0)^{\mathrm{e}}$ \\
\hline \multirow[t]{2}{*}{10} & Large antral follicle* & $30(1.7)$ & $821(550-1030)$ & $69(55-85)$ & $3.3(2.0-6.0)^{\mathrm{e}}$ \\
\hline & & $\overline{1775}$ & & & \\
\hline
\end{tabular}

*, Metaphase-II oocytes were placed.

**, Diameters of follicles and oocytes differ significantly among each stage, except for between follicles at Stages 7 and 8 , and between oocytes at Stages 4 and 10 .

${ }^{\mathrm{a}-\mathrm{e}}$, Means with different superscripts differ significantly.

rearrangement of the stages of follicular development reported prevously ${ }^{27,30)}$, corresponds principally to the number of layers of the follicular epithelial cells especially in the early growing follicular stage : e.g. Stage 0 is primordial follicle stage ; Stage 1 is primary follicle stage; Stage 0.5 is a stage between Stage 0 and Stage 1 where the oocyte was not surrounded completely with a single layer of follicular cells. A good correlation between diameters of the follicles and the stage of follicular development was found as shown in Table 1. By using. ODO method, a total of 369 fractured follicles were obtained from 39 females and their dynamic structures were divided into 3 groups : (1) primordial and primary follicles (Stages 0-1), (2) growing preantral follicles (Stages 1.5 to 6) and (3) antral follicles (Stages 7 to 10 ). Stage 10 is so-called Graafian follicle stage including the Metaphase-II oocyte.

\section{(1) Primordial and primary follicles}

Primordial follicles were round structure consisting of an oocyte surrounded by a single layer of very flattened follicular epithelial cells (Figs. $1 \mathrm{a}$ and b), with no intercellular spaces between both types of cells (Fig. 1 b). A thin and regular basal lamina separated the follicle from the numerous stroma cells.

Primary follicles showed the cuboidal and polyhedral follicular epithelial cells (Figs. $1 \mathrm{a}$ and c). Very few microvillous processes $(0.09 \pm 0.02 \mu \mathrm{m}$ in thickness) were recognizable in the limited spaces irregularly distributed between the oocyte and the follicular epithelial cells (Fig. 1d). Numerous organelles, such as mitochondria, Golgi complex and some lamellae, were associated with a delicate network of the cytoskeleton.

\section{(2) Growing preantral follicles}

The follicles increased in diameter progressively at this stage (Table 1), and were characterized by an increasing number of stratified follicular epithelial 


\section{SUZUKI, FUKUDA and TOYOKAWA}

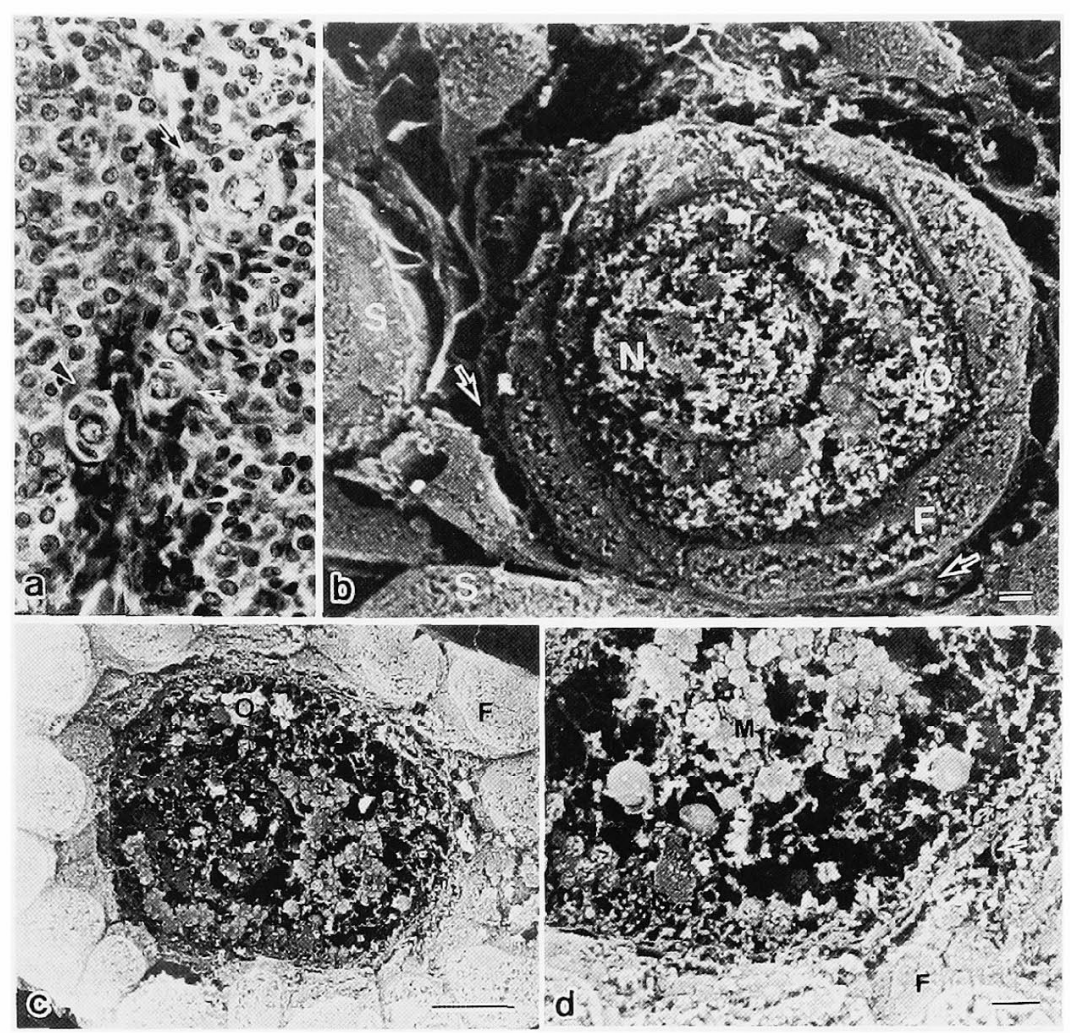

Fig. 1. Primordial and primary follicles.

(a) Light micrograph of cortical stroma of an ovary, showing a nest of follicles. Note two primordial follicles (Stage 0, small arrows) and one primary follicle (Stage 1, large arrow). A follicle at Stage 0.5 is seen on the left (arrow head). $\times 250$. (b)-(d) SEM-ODO method. O, oocyte ; F, follicular epithelial cells. Bar represents $1 \mu \mathrm{m}$ in (b) and (d) and $5 \mu \mathrm{m}$ in (c). (b) Fracture of a primordial follicle. An oocyte with a single layer of flattened follicular epithelial cells has a spheroid ooplasm including a round nucleus $(\mathrm{N})$. In the ooplasm close to nuclear surface (on the right side of nucleus), a mass of spherical organelles corresponding to mitochondria can be seen. A thin basal lamina (arrows) separates the follicle from the numerous stroma cells (S). (c) Fracture of a primary follicle. Cuboidal and polyhedral follicular epithelial cells closely appose to an oocyte, where the intercellular spaces are rarely found. Higher magnification of (c) reveals occasional development of microvillous processes (arrow) on the follicular epithelial cells. Note many spherical organelles and lamellae corresponding to mitochondria (M) and Golgi complex (G), supported by a network of cytoskeleton.

cells around the oocyte (Fig. 2 a). The ZP was histologically recognized as a uniform thin layer between the oocyte and the surrounding follicular epithelial cells at Stages 3 to 4 (Fig. 2 a), which increased gradually in thickness as the follicle developed (Table 1). The oocyte reached its full size around Stage 5 (74-76 $\mu \mathrm{m}$ in diameter).

The ZP of fractured follicles macerated for 1 day was not removed and recognized as an amorphous layer, separating the oocyte from the surrounding follicular epithelial cells (Fig. 2 b). When the specimens were subjected to longer maceration (2-3 days), the ZP was completely dissolved; thereby the cytoplasmic processes between the oocyte and the follicular epithelial cells were exposed in the intercellular spaces (Figs. 2c and d). Thickness of the

Anim. Sci. J. 72 (2) : 107-116, 2001 


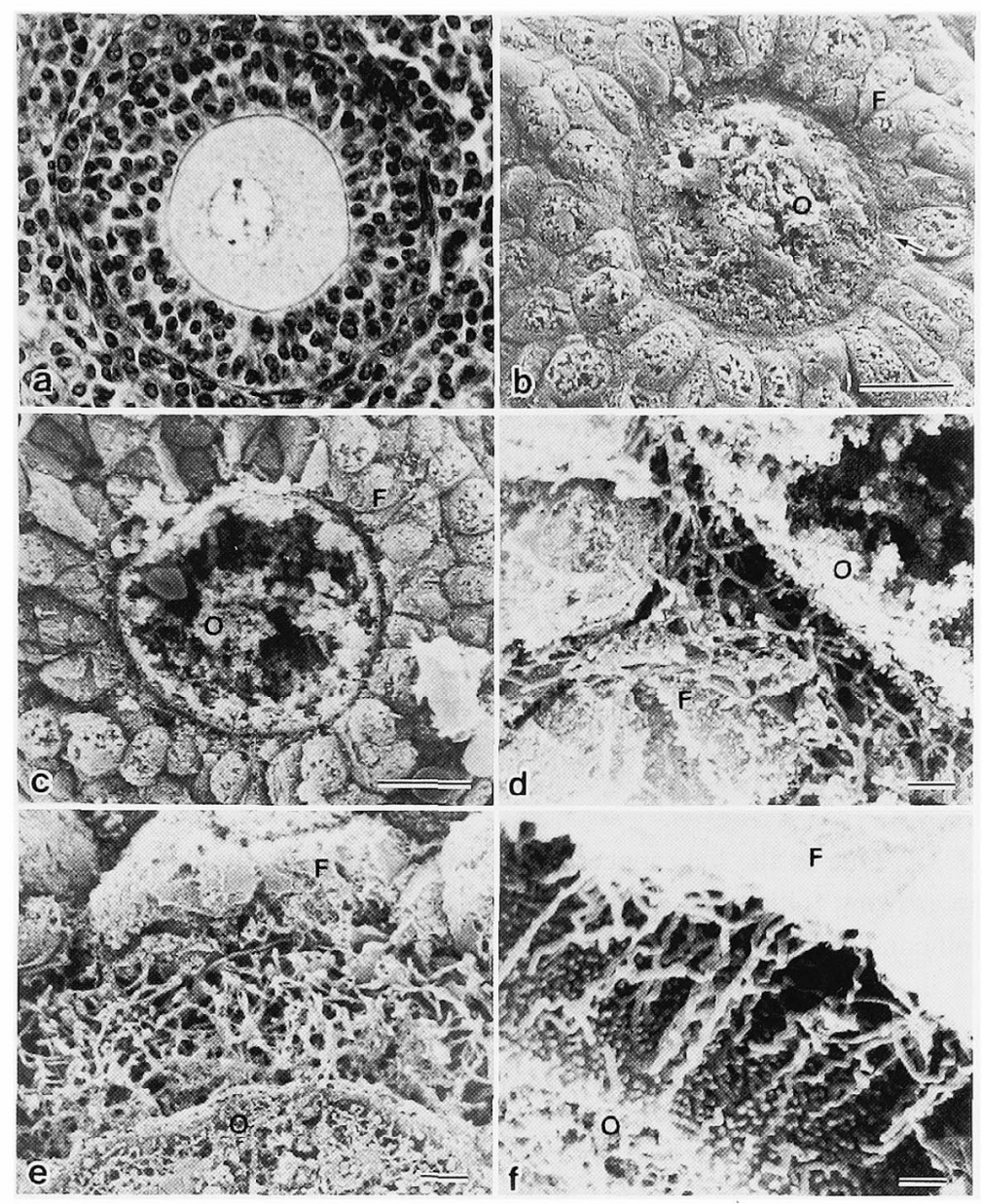

Fig. 2. Growing preantral follicles.

(a) Light micrograph of a Stage 3 follicle, with 3 layers of follicular epithelial cells around the oocyte. Zona pellucida is forming. $\times 250$. (b)-(f) SEM-ODO method. O, oocyte ; F, follicular epithelial cells. Bar represents $10 \mu \mathrm{m}$ in (b) and (c) and $1 \mu \mathrm{m}$ in (d)-(f). (b) Fracture of a Stage 3 follicle after short maceration. Zona pellucida (arrow) is noticed as a distinct layer. (c) Fracture of another Stage 3 follicle after long maceration. Notice remarkable dissolution of the matrix of the ooplasm compared to (b). Zona pellucida is also completely dissolved and numerous cytoplasmic processes of the follicular epithelial cells are exposed. (d) Higher magnification of (c) shows ramified cytoplasmic processes in the intercellular spaces between the oocyte and the follicular epithelial cells. (e) Fracture of a Stage 5 follicle. Notice that the cytoplasmic processes of the follicular epithelial cells are developing well compared to (d). (f) Fracture of a Stage 6 follicle. Notice that cytoplasmic processes of the follicular epithelial cells are intermingled with microvilli on the oolemma.

cytoplasmic processes increased significantly in the follicles from Stages 2 to $3(0.14+0.01 \mu \mathrm{m}$ and $0.18+$ $0.01 \mu \mathrm{m}$, respectively, $\mathrm{P}<0.05$ ) but thereafter no remarkable increase was noted. These processes were tortuous and ramiform in the early growing follicles
(Fig. 2d), whereas they increased greatly in number and in length at more advanced stages, looking like slender microvilli (Figs. 2e and f). Some of them intermixed microvilli on the oolemma (Fig. $2 \mathrm{f}$ ).

About half of oocytes in this follicular group

Anim. Sci. J. 72 (2) : 107-116, 2001 


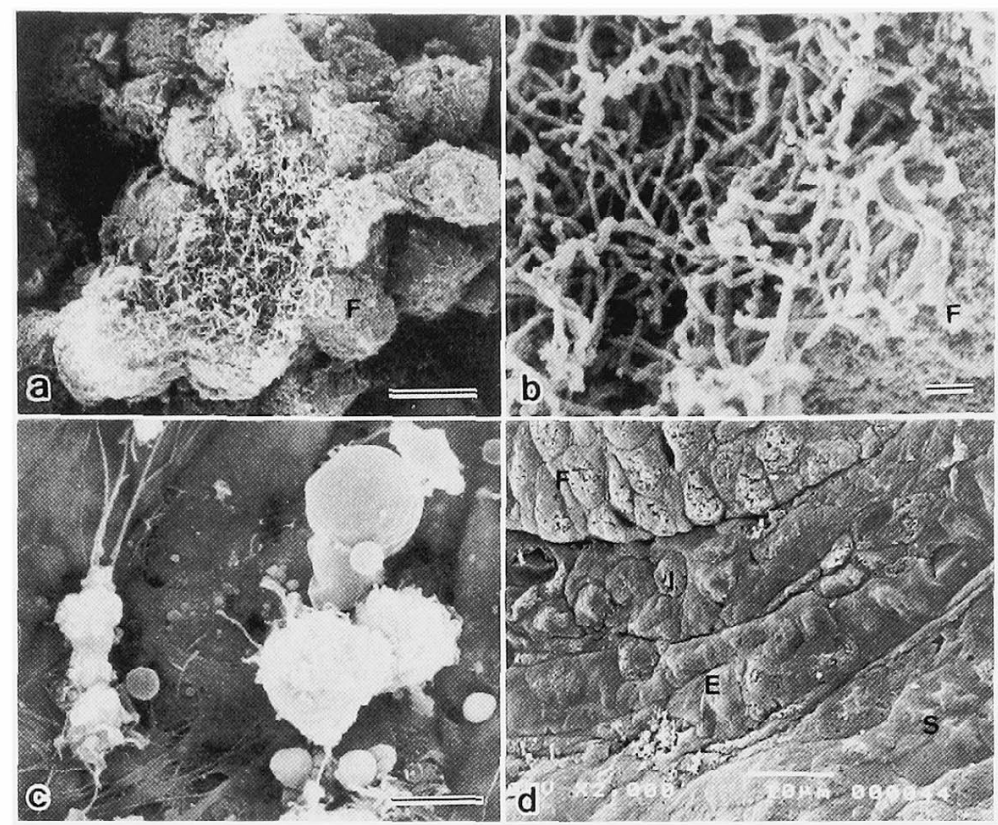

Fig. 3. Due to the long maceration by ODO method, the different components of the growing follicle are evident.

F, Follicular epithelial cells. SEM-ODO method. Bar represents $1 \mu \mathrm{m}$ in (b) and $10 \mu \mathrm{m}$ in (a), (c) and (d). (a) The innermost layer of follicular epithelial cells with the cytoplasmic processes corresponding to the area where the oocyte and the zona pellucida were previously located. (b) Higher magnification of (a) allows the details of the cytoplasmic processes to be seen. (c) Follicular epithelial cell mass has been dissolved by maceration, thereby the inner surface of the internal theca layer can be seen. Some cellular components on the surface display developing pseudopodia. (d) Fractured theca layer of a Stage 4 follicle. The tunica interna thecae folliculi (I) and the tunica externa thecae folliculi (E) can be distinguished. S, stroma cells.

(56/104) had fallen away as a consequence of the fracture and ODO maceration, thus offering a favorable view of the other follicular components. In some instance, fine structures of the developing cytoplasmic processes of follicular epithelial cells were fully revealed around the area where the oocyte and the $\mathrm{ZP}$ were previously located (Figs. $3 \mathrm{a}$ and $\mathrm{b}$ ). In the other instance, the follicular epithelial cell masses were dissociated completely from the fractured follicles, thereby showing the inner surface of the basement membrane between the follicular epithelial cells and the theca interna cells (Fig. $3 \mathrm{c}$ ). Some thin microvillous structures were found on the surface of the basement membrane. The theca interna and theca externa cells were recognizable on the fractured surface of follicles with 4 layers of follicular epithelial cells (Fig. 3d).

\section{(3) Antral follicles}

Since the majority of oocyte-follicular epithelial cell mass $(92 \%, n=176)$ was lost from the fractured surfaces, the oocytes were observed by SEM only in $8 \%(15 / 176)$ of the antral follicles examined. The follicular fluid was progressively accumulated, consequently giving rise to a large cavity. The follicular epithelial cells were identified as granulosa cells. Peripheral dislocation of the oocyte and surrounding granulosa cells concomitantly occurred to form the cumulus oophorus (Figs. $4 \mathrm{a}$ and b) as the follicular antrum increased. The $\mathrm{ZP}$ reached the maximum thickness, but the diameter of the oocyte decreased significantly at Metaphase II (Table 1). The innermost layer of cumulus cells, referred to as corona 


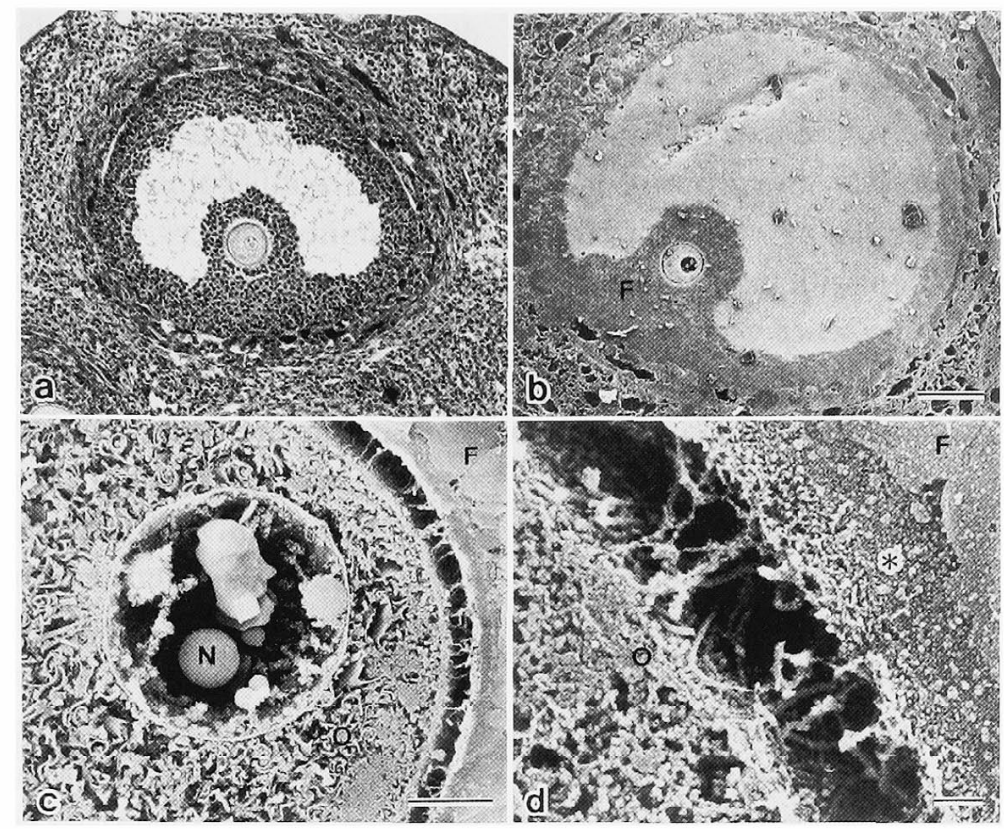

Fig. 4. Antral follicles.

(a) Light micrograph of a Stage 9 follicle, showing formation of large follicular antrum. $\times 62$. (b)-(d) A Stage 9 follicle. SEM-ODO method. O, oocyte ; F, follicular epithelial cells (so-called cumulus cells). Bar represents $100 \mu \mathrm{m}$ in (b), $10 \mu \mathrm{m}$ in (c) and $1 \mu \mathrm{m}$ in (d). (b) Fracture of an antral follicle. Note accumulation of follicular fluid and formation of the cumulus oopharus. (c) Higher magnification of (b). The oocyte possesses a round nucleus including nucleolus (N). Note numerous globular and lamellar organelles in the ooplasm. (d) Higher magnification of (b). The inner layer of zona pellucida is completely dissolved, but the outer layer (asterisk) is still located even after the long maceration.

radiata cells, still projected a number of long and irregular cytoplasmic processes $(0.18 \pm 0.01 \mu \mathrm{m}$ in diameter) towards the oocyte (Figs. $4 \mathrm{c}$ and $\mathrm{d}$ ). As mentioned above, matrix of the $\mathrm{ZP}$ of the growing follicles was completely removed after 3 days of maceration. In the antral follicles, however, the ZP was not dissolved completely, where the inner ZP layer was normally dissolved first with the outer ZP layer remaining even after 3 days of maceration (Fig. 4d), suggesting heterogeneity of the $\mathrm{ZP}$ at the antral follicle stage.

\section{Discussion}

The present histological observations clearly demonstrated that the diameter of the follicles was closely correlated with the stage of follicular development. Diameters of the follicles at different develop- ing stages reported here were almost similar to those measured by Roy and Greenwald ${ }^{30)}$, except for data on the primordial follicles which were not included in their classification. Although no thecal layer was found histologically until hamster oocytes were surrounded by 7 or 8 layers of follicular epithelial cells ${ }^{30)}$, the SEM-ODO method revealed that hamster ovarian follicles were surrounded by external and internal thecal layers as early as Stage 4, with 4 layers of follicular cpithelial cells. Around this stage, a growing oocyte was surrounded by a well-defined ZP, which is in accordance with the observation using an immunofluorescence technique ${ }^{19)}$. The present results also show that the diameter of the oocytes increased dramatically during the early growing follicular stage, reached the full size around Stage 5, but decreased at Stage 10. Decreased diameter of the 


\section{SUZUKI, FUKUDA and TOYOKAWA}

oocytes at maturational status has been observed previously $^{32 !}$.

The antral follicles increased resistance of the $\mathrm{ZP}$ to the ODO maceration compared to the growing preantral follicles. Apparent "hardening" may not only be related to the ZP maturation within the follicular environment, but also to the presence or absence of diffusible factor(s) produced by the follicular epithelial cells that protects the ZP from hardening ${ }^{6)}$. Insolubility of the ZP after the ODO maceration was previously observed in the IVM porcine oocytes ${ }^{34)}$. Spontaneous hardening of the $\mathbf{Z P}$ has also been observed in mouse oocytes cultured in vitro ${ }^{6}$. The other possibility is that the $\mathrm{ZP}$ hardening is caused by the premature release of cortical granules ${ }^{25}$.

It is noteworthy that the ZP layers show heterogeneity in response for the ODO maceration, where the inner layer of the $\mathrm{ZP}$ was dissolved, but the outer layer was not dissolved even after 3 days of maceration. Interestingly, a reverse relationship was noted in the porcine $\mathbf{Z P}$, where the outer layer was dissolved first $^{34)}$. These differences could be due to the differences in the changes of ZP properties between both species. Several studies have shown the apparent heterogeneity of the ZP, showing that a higher density of lectin- and antibody-binding sites exist at the exterior compared to the interior region of the $\mathrm{ZP}^{10.39)}$. SEM observation revealed that the outer surface of the hamster ZP was fenestrated, while the internal surface appeared irregular and particulate ${ }^{28)}$. Keefe et al. ${ }^{14)}$ have recently observed the distinct layers of hamster ZP by pol-scope. The layered structure of the hamster ZP observed in our materials is consistent with the previous observations ${ }^{10,14,28,39)}$. Talbot and DiCarlantonio $^{35}$ ) have reported that extracellular matrix involved in the hamster cumulus-oocyte complexes extend into the outer one third of the ZP. In cattle, the role of oviductal factor(s) on the block to polyspermy has been suggested ${ }^{7)}$. Since the maturing/matured $\mathrm{ZP}$ appeared to be more insoluble to maceration than did the immature $\mathrm{ZP}$ as described above, the effect of extracellular matrix or oviductal factor(s) on the properties of the hamster $\mathrm{ZP}$ is a matter for further investigation.

The present observations clearly showed three- dimensionally changes in follicular epithelial celloocyte connections. At primordial follicular stage, the hamster oocyte was in contact with surrounding follicular epithelial cells. In some primary follicles, very limited spaces between the oocyte and the follicular epithelial cells was partially formed, probably due to the secretion of $\mathrm{ZP}$ components by the growing oocyte as reported by Léveille et al. ${ }^{19)}$. Wassarman and Bleil ${ }^{38)}$ have also reported that mouse oocytes of 35-62 $\mu \mathrm{m}$ are able to synthesize glycoproteins in vitro. Diameters of these oocytes correspond to the hamster oocytes at Stages 1.5 to 3 (Table 1). Since we have observed slender microvillous processes in the limited spaces between the oocyte and the follicular epithelial cells at the primary follicle stage, it can be proposed that the follicular epithelial cells may start to extend microvillous processes towards the oocyte, once they are out of contact with the oocyte due to accumulation of the ZP components secreted. Then, the cytoplasmic processes keep growing to intermix with microvilli on the oocyte surface during $\mathrm{ZP}$ formation and consequently they would be embedded by well-defined ZP. TEM observations on hamster oocytes by Weakley ${ }^{41,42)}$ and Roy and Greenwald ${ }^{30)}$ showed that the follicular epithelial cells extend the cytoplasmic processes towards the oocyte through the $\mathrm{ZP}$ to reach the oolemma as reported in the different species ${ }^{4,11,44}$. Together, these observations suggest that the cell-to-cell communications via the cytoplasmic processes between the oocyte and the somatic cells begins to form at Stage 1 and may be established until Stage 3 in the hamster follicles. The importance of gap junctions in oocytesomatic cell communication has been recognized $^{3-5,9,11,13,15,16,22,37,44)}$. Yu and $\operatorname{Roy}^{43)}$ have suggested that oocyte-follicular epithelial cell interaction is important in in vivo folliculogenesis of the hamster prenatal ovary, too. However, recent studies have addressed questions regarding the role of gap junction mediated communication during oogenesis ${ }^{29)}$. In addition, Albertini and Rider $^{2)}$ have reported the presence of two distinct types of transzonal cytoplasmic processes by fluorescence techniques in a species-specific manner. Further studies are needed to clarify functional significance of 
different types of the cytoplasmic processes as well as those of gap junctions.

In summary, the present results show usefulness of the SEM-ODO method for studying cell-to-cell communications. Delicate architectures of the follicular epithelial cell-oocyte connections are well preserved until early growing follicles. In the antral follicles, however, oocytes were often lost from the fractured surface. This suggests that the cell connections between the oocyte and the surrounding granulosa cells may be more fragile at the antral follicle stage than the earlier stages. Extreme low rate of the oocytes detected on the fractured surface of such follicles requires further improvement of this method.

\section{References}

1) Albertini DF, Anderson E. The appearance and structure of intercellular connections during the ontogeny of the rabbit ovarian follicle with particular reference to gap junctions. Journal of Cell Biology, 63: 234-250. 1974.

2) Albertini DF, Rider V. Pattern of intercellular connectivity in the mammalian cumulus-oocyte complex. Microscopy Research and Technique, $27:$ 125-133. 1995.

3) Allworth AE, Albertini DF. Meiotic maturation in cultured bovine oocytes is accompanied by remodeling of the cumulus cell cytoskeleton. Developmental Biology, 158: 101 112. 1993.

4) Anderson E, Albertini DF. Gap junctions between the oocyte and companion follicle cells in the mammalian ovary. Journal of Cell Biology, $71: 680^{-686}$. 1976.

5) Buccione R, Schroeder AC, Eppig JJ. Interactions between somatic cells and germ cells throughout mammalian oogenesis. Biology of Reproduction, 43 : 543-547. 1990.

6) De Felici M, Siracusa G. "Spontaneous" hardening of the zona pellucida of mouse oocytes during in vitro culture. Gamete Research, 6 : 107-113.

7) Duby RT, Hill JL, O'Callaghan D, Overstrom EW, Boland MP. Changes induced in the bovine zona pellucida by ovaine and bovine oviducts. Theriogenology, $1997 ; 47: 332$ (Abstr).

8) Eppig JJ. The relationship between cumulus celloocyte coupling, oocyte meiotic maturation, and cumulus expansion. Developmental Biology, 89 : 268272. 1982.
9) Eppig JJ. Intercommunication between mammalian oocytes and companion somatic cells. Bioessay, 13 : 569-574. 1991.

10) Familiari G, Nottola SA, Macchirelli G, Micara G, Aragona C, Motta PM. Human zona pellucida during in vitro fertilization : An ultrastructural study using saponin, ruthenium red, and osmiumthiocarbohydrazide. Molecular Reproduction and Development, $32:$ 51-61. 1992.

11) Gilula NB, Epstein ML, Beers WH. Cell-to-cell communication and ovulation. A study of the cumulusoocyte complex. Journal of Cell Biology, 78 : 58-75. 1978.

12) Haghighat N, Van Winkle LJ. Developmental change in follicular cell-enhanced amino acid uptake into mouse oocytes that depends on intact gap junctions and transport system Gly. Journal of Experimental Zoology, $253: 71-82.1990$.

13) Hyttel P. Bovine cumulus-oocyte disconnection in vitro. Anatomy and Embryology, 176: 41-44. 1987.

14) Keefe D, Tran P, Pellegrini C, Oldenbourg R. Polarized light microscopy and digital image processing identify a multilaminar structure of the hamster zona pellucida. Human Reproduction, 12:12501252. 1997.

15) Kruip TAM, Cran DG, van Beneden TH, Dieleman SJ. Structural changes in bovine oocytes during final maturation in vivo. Gamete Research, $8: 29-47$. 1983.

16) Laurincik J, Kroslak $P$, Hyttel $P$, Pivko J, Sirotkin AV. Bovine cumulus expansion and corona-oocyte disconnection during culture in vitro. Reproduction, Nutrition, Development, 32 : 151-161. 1992.

17) Laurincik J, Pivko J, Kroslak P. Cumulus oophorus expansion of bovine oocytes cultured in vitro: A SEM and TEM study. Reproduction in Domestic Animals, $27:$ :217-228. 1992.

18) Lawrence TH, Beers WH, Guila NB. Transmission of hormonal stimulation by cell-to-cell communication. Nature, $272: 501-506.1978$.

19) Léveille $M C$, Roberts $K D$, Chevalier $S$, Chapdelaine A, Bleau $G$. Formation of the hamster zona pellucida in relation to ovarian differentiation and follicular growth. Journal of Reproduction and Fertility, 79 : 173-183. 1987.

20) Makabe S, Naguro T, Motta PM. A new approach to the study of ovarian follicles by scanning electron microscopy and ODO maceration. Archives of Histology and Cytology, $55: 182-190.1992$.

21) McGaughey RW, Racowsky C, Rider V, Baldwin K, 


\section{SUZUKI, FUKUDA and TOYOKAWA}

DeMarais AA,Webster SD. Ultrastructural correlates of meiotic maturation in mammalian oocytes. Journal of Electron Microscopy Technique, $16: 257-$ 280. 1990.

22) Moor RM, Smith MW, Dawson RM. Measurement of intercellular coupling between oocytes and cumulus cells using intracellular markers. Experimental Cell Research, $126: 15-29.1980$.

23) Motlik J, Fulka J, Fléchon JE. Changes in intercellular coupling between pig oocytes and cumulus cells during maturation in vivo and in vitro. Journal of Reproduction and Fertility, 76:31-37. 1986.

24) Motta PM, Makabe $S$, Naguro T, Correr S. Oocyte follicle cells association during development of human ovarian follicle. A study by high resolution scanning and transmission electron microscopy. Archives of Histology and Cytology, 57 : 369-394, 1994.

25) Nicosia SV, Wolf DP, Inoue M. Cortical granule distribution and cell surface characteristics in mouse eggs. Developmental Biology, 57 : 56-74. 1977.

26) Orsini MW. The external vaginal phenomena characterizing the stages of the estrus cycle, pregnancy, pseudopregnancy, lactation and the anestrous hamster. Mesocricetus auratus. Proceedings of the Animal Care Panel, 11 : 193-206. 1961.

27) Pedersen T, Peters H. Proposal for a classification of oocytes and follicles in the mouse ovary. Journal of Reproduction and Fertility, 17 : 555-557. 1968.

28) Phillips DM, Shalgi R. Surface properties of the zona pellucida. Journal of Experimental Zoology, 213:18. 1980.

29) Phillips DM, Denkel N. Maturation of the rat cumulus-oocyte complex : structure and function. Molecular Reproduction and Development, $28: 297-$ 306. 1991.

30) Roy SK, Greenwald GS. An enzymatic method for dissociation of intact follicles from the hamster ovary: histological and quantitative aspects. Biology of Reproduction, 32: 203-215. 1985.

31) Suzuki H, Yang X, Foote RH. Surface alterations of the bovine oocyte and its investments during and after maturation and fertilization in vitro. Molecular Reproduction and Development, 38 : 421-430. 1994.

32) Suzuki H, Fujiwara T, Yang $X$. Surface ultrastructural characteristics of the hamster oocyte and its investments during in vivo maturation. Journal of Mammalian Ova Research, 14 : 191-197. 1997.
33) Suzuki H, Presicce GA, Yang X. Differential surface ultrastructural characteristics and volumetric dynamics of bovine oocytes during maturation in vivo versus in vitro. Journal of Mammalian Ova Research, $15: 49-62.1998$.

34) Suzuki H, Jeong B-S, Yang X. Dynamic changes of cumulus-oocyte cell communication during in vitro maturation of porcine oocytes. Biology of Reproduction, $63: 723-729.2000$.

35) Talbot P, DiCarlantonio G. The oocyte-cumulus complex : ultrastructure of the extracellular components in hamsters and mice. Gamate Research, 10 : 127 142. 1984.

36) Thibault C, Szollosi D, Gerard M. Mammalian oocyte maturation. Reproduction, Nutrition, Development, $27: 865-896.1987$.

37) Vanderhyden BC, Telfer EE, Eppig JJ. Mouse oocytes promote proliferation of granulosa cells from preantral and antral follicles in vitro. Biology of Reproduction, 46:1196-1204. 1992.

38) Wassarman PM, Bleil JD. The role of zona pellucida glycoproteins as regulators of sperm-egg interactions in the mouse. In : Cellular Recognition. (Frazier WA, Glaser L, Gottlieb DI eds.) 845-863. Alan R. Liss. New York. 1982.

39) Wassarman PM. Zona pellucida glycoproteins. Annual Review of Biochemistry, 57 : 415-442. 1988.

40) Wassarman PM. The mammalian ovum. In : The Physiology of Reproduction. (Knobil E, Neill JD eds.) 69-102. Ravan Press. New York. 1988.

41) Weakley BS. Electron microscopy of the oocyte and granulosa cells in the developing ovarian follicles of the golden hamster (Mesocricetus auratus). Journal of Anatomy, 100: 503-534. 1966.

42) Weakley BS. Light and electron microscopy of developing germ cells and follicle cells in the ovary of the golden hamster : twenty-four hours before birth to eight days post partum. Journal of Anatomy, 101 : 435-459. 1967.

43) Yu N, Roy SK. Development of primordial and prenatal follicles from undifferentiated somatic cells and oocytes in the hamster prenatal ovary in vitro. Biology of Reproduction, 61 : 1558-1567. 1999.

44) Zamboni L. Fine morphology of the follicle wall and follicle cell-oocyte association. Biology of Reproduction, $10: 125-149.1974$. 